\title{
SOBRE O ANTICARTESIANISMO COM RELAÇÃO AOS PRIMEIROS PRINCÍPIOS DO CONHECIMENTO EM PASCAL E HUME
}

Dario Galvão*

\begin{abstract}
Resumo: O objetivo deste trabalho é refletir acerca da perspectiva anticartesiana que se manifesta nas obras de Pascal (1623-62) e Hume (1711-76), especificamente no que se refere à concepção filosófica dos primeiros princípios do conhecimento. Partindo da enunciação da mathesis universalis em Descartes, buscamos identificar como Pascal e Hume apresentam uma posição alternativa, assim como refletir acerca das semelhanças e divergências entre esses dois autores. As principais fontes de Pascal a serem consideradas são o opúsculo Do Espírito Geométrico (1656, publicado parcialmente em 1728) e o fragmento 72 (edição Brunschvicg) dos Pensamentos (1670). No caso de Hume, focaremos na Parte I do Livro I do Tratado acerca da natureza humana (1739-40) e na Investigação sobre o entendimento humano (1748).
\end{abstract}

Palavras-chave: Hume, Pascal, anticartesianismo, princípios, conhecimento.

Essa disciplina deve, de fato, conter os primeiros rudimentos da razão humana e estender sua ação até fazer jorrar as verdades de qualquer assunto que seja. Falando livremente, ela é preferível a qualquer outro conhecimento transmitido humanamente, visto que é a fonte de todas as outras: é essa a minha persuasão. (Descartes 2, p. 23)

Vemos nesse trecho um prelúdio para a enunciação da conhecida mathesis universalis, disciplina fundamental para o conhecimento em geral segundo Descartes, apresentada na Regra IV das Regras para orientação do espírito, obra escrita em 1628, inacabada e publicada apenas em 1701. Escrita pouco mais de uma década antes da publicação de obras centrais como o Discurso do Método (1637) e as Meditações Metafísicas (1641), é possível encontrar nela a formação da concepção cartesiana acerca da ciência, no que diz respeito a seu ponto de vista filosófico, que tanto teve efeito na história da filosofia. Em paralelo à produção de tratados de física e matemática, vemos nessa obra a iminência de um pensamento filosófico acerca do estatuto das verdades científicas, ou seja, acerca da necessidade de se responder a um problema de natureza da possibilidade do conhecimento em geral. De onde provém as certezas mais evidentes que carregamos? Como é possível que estas certezas não possam ser postas em dúvida?

\footnotetext{
* Graduando no Departamento de Filosofia FFLCH/USP, bolsista PET/MEC, dario.galvao@gmail.com.
} 
A consideração da matemática universal ocorre com o objetivo de tratar desse tipo de problema. Não se trata de pensar sobre a natureza do objeto, como faz a física, tampouco sobre a ordem das figuras ou dos números, como faz a matemática; trata-se, sobretudo, de se questionar a respeito da origem de todo conhecimento possível. O problema é filosófico antes de ser científico, por isso essa disciplina fundamental deve ser considerada anterior à própria metafísica, uma vez que é através dela que se dispõe dos primeiros passos para todo e qualquer conhecimento, algo como a forma de conhecer. Assim, antes de qualquer ato de conhecer, faz-se necessário que se saiba o como se pode conhecer - só desse modo se pode livrar a ciência de uma ineficaz caça ao tesouro. ${ }^{1}$ Essa seria uma importante verdade do método cartesiano: há uma natureza específica do conhecimento humanamente transmitido, e a consideração dessa natureza deve ser o primeiro ato epistemológico do entendimento. Daí tira-se que há certos princípios da razão que são fundamentos para o conhecimento em geral, antes mesmo de qualquer conhecimento em particular.

É de se surpreender a ousadia do projeto cartesiano. O objetivo seria o de fundar a ciência exclusivamente sobre princípios que podem ser apreendidos pela razão humana. E vai ainda mais longe: não seria apenas necessário que voltemos à razão para fundar o conhecimento, mas também que consideremos que todo o conhecimento possível expresse a todo momento essa natureza racional. Há a declaração de uma faculdade que constitui a unidade e a universalidade do saber. $\mathrm{Ou}$ seja, não há nada por natureza que seja impossível que a razão conheça. Se há algo que não pode ser conhecido pela razão, é porque não pode ser por direito objeto de conhecimento - como é o caso dos dados provenientes dos sentidos - e não porque a razão seria incapaz de conhecer. Não é possível que haja qualquer tipo de conhecimento se não houver a operação do entendimento através de Ordem e Medida. E são estes últimos o objeto da disciplina primeira, da qual toda a árvore do saber cartesiano depende. $^{2}$

Esta centralidade da razão deve ser verificada com rigor à luz da metafísica cartesiana. A afirmação de que esta última é posterior à mathesis universalis pode gerar confusão; afinal, como algo pode ter valor epistemológico e ser anterior à ciência que estabelece a primeira verdade do conhecimento? Na terceira meditação, vemos Descartes conceber a ideia de Deus como infinito e percebemos o estabelecimento do ego como o mediador entre o infinito e o finito. A ideia de Deus é 
concebida com extrema clareza e evidência e é dela que devem ser deduzidas todas as outras verdades. É a comunicabilidade entre Deus e o ego, assim como entre o ego e o mundo, que dá, para Descartes, a possibilidade e a natureza do conhecimento. Ao estabelecer a comunicabilidade, a metafísica legitima a mathesis universalis; e esta última permite portanto o conhecimento verdadeiro do mundo, que se dá através da direção do espírito conforme seus critérios racionais. O trabalho da racionalidade, enquanto operação de conhecimento, parece adquirir, dessa forma, estatuto de verdade metafísica, estabelecendo a si próprio como único modo de conhecer possível. Isso não quer dizer que não possamos, sob outro ponto de vista, considerar a mathesis universalis como anterior à metafísica: no sentido em que deve ser identificada com o método cartesiano, como a forma do conhecimento, enquanto a metafísica já seria o passo de estabelecimento de verdades, de conteúdo. No primeiro caso, temos os pressupostos metafísicos da mathesis; no segundo, temos a metafísica enquanto ciência e, por isso, parte da mathesis enquanto raiz da árvore do saber. Tanto do ponto de vista dos pressupostos, quanto do ponto de vista da ciência, o entendimento é concebido como fundador do conhecimento, assim como determina sua natureza.

Entretanto, o que dizer a respeito da ciência experimental, que se realiza a despeito da consideração da mathesis universalis, da metafísica e de toda reflexão acerca da possibilidade do conhecimento? Não seria esse um caso que contradiz a perspectiva cartesiana? Na realidade, ao contrário disso: esse é um ótimo exemplo para Descartes. O fato de que as explicações da física tornam-se tão seguras se explica porque o objeto de conhecimento coincide com a natureza racional do pensamento. A natureza é passível de ser tomada em termos matemáticos porque tudo aquilo que existe se dá segundo essa natureza racional. O objeto do conhecimento é racional, e como a razão pode conhecer aquilo que é (ou seja, a essência das coisas), decorre que a natureza se dá segundo critérios racionais.

No entanto, a grande diferença que vemos, quando consideramos a prática da ciência dita cega, é a respeito da postura científica daquele que a pratica. Newton, grosso modo, tinha suas hipóteses não apenas verificadas na experiência, mas também formuladas a partir da experiência. Segundo essa perspectiva, o papel da razão seria o de formular as proposições na tentativa de explicar os fatos observados na natureza; e não o de ser a base legitimadora da natureza do objeto em geral. Nesse caso, não há 
necessidade de se estabelecer o objeto de conhecimento como ser racional, mas apenas de considerar racionalmente algo que se apresenta para o homem e que se demonstra, quem sabe, para além da razão.

O objetivo desse trabalho é ver como essa perspectiva anticartesiana a respeito da natureza do conhecimento não se limita à prática da ciência experimental, mas adquire estatuto filosófico no interior de dois grandes autores que, apesar de compartilharem algumas posições, são radicalmente diferentes em tantas outras. Através do exame de como Pascal (1623 - 1662) e Hume (1711 - 1776) tratam do problema dos primeiros princípios do conhecimento, buscaremos identificar uma posição alternativa àquela apresentada por Descartes, assim como refletir sobre pontos de semelhanças e divergências entre esses dois autores. As principais fontes de Pascal a serem consideradas são o opúsculo Do Espírito Geométrico (1656, publicado parcialmente em 1728) e o fragmento 72 (edição Brunschvicg), dos Pensamentos (1670). No caso de Hume, focaremos na Parte I do Livro I do Tratado acerca da natureza humana (1739-40) e na Investigação sobre o entendimento humano (1748).

\section{Pascal: o ponto intermediário e a refutação do saber universal.}

Enquanto para Descartes há um modo de conhecimento fundamental que perpassa todo o conteúdo das ciências, para Pascal isso não ocorre. Para ele não existiria apenas um método, mas uma diversidade deles. ${ }^{3}$ Propomos nesse trabalho que essa perspectiva epistemológica seja compreendida através da consideração pascaliana acerca da natureza humana. Assim como fará Hume, o estatuto do conhecimento é decorrência de um posicionamento acerca do que é o homem. O que não é de todo diferente em Descartes, uma vez que é da investigação da essência do entendimento que ele parte para a fundamentação de suas verdades. A divergência entre este último e os outros dois está mais evidente no modo distinto como concebem a natureza humana: consideração ou não da absoluta centralidade e precedência da faculdade cogitativa do pensamento. A posição acerca dos primeiros princípios não é mais do que uma decorrência necessária dessa posição antropológica (o que é mais claro em Hume e Pascal).

Em Pascal, sabe-se que a religião cristã é determinante para o horizonte de sua antropologia, o que certamente não acontece para Hume. Veremos que apesar das premissas serem radicalmente divergentes, isso não se repete com o resultado: ambos 
destacam a limitação da razão humana, inclusive demonstrando, cada qual a sua maneira, como o conhecimento dos primeiros princípios vai além da faculdade cogitativa, ou entendimento, dependendo mais especificamente de um ato sensitivo, da ordem do sentimento.

"Nosso Deus é um Deus escondido": verdade extraída das Escrituras e levada às últimas consequências pelos seguidores de Port-Royal, corrente religiosa francesa à qual Pascal filia-se e que no século XVII representa lugar central de contestação política e religiosa. Dada a oposição dos jansenistas (nome da corrente), chegam a ser considerados heréticos pela Igreja, sob a acusação de que sua doutrina diverge da verdade revelada na Bíblia. Um dos pontos centrais dessa disputa encontra-se na radicalidade que os ditos heréticos adotavam para a verdade do Deus oculto. Segundo eles, a corrupção humana é tamanha que a verdade encontra-se de fato e de direito oculta, e que não pode aparecer senão por sinais. ${ }^{4}$ A degradação decorrente do pecado original teria colocado o homem numa condição completamente patológica, de completa escuridão. A separação com Deus é absoluta e resulta numa noite em que nada pode ser sabido com certeza a respeito da vontade ou ações divinas e até mesmo a respeito da própria condição humana. Mesmo esta última permanece, em última instância, um mistério - expresso pelo próprio pecado original. O homem fica preso a um mundo corrompido, numa condição de completa obscuridade a respeito da verdade e, por isso, diz-se sinais, porque há a ideia de que o homem está cercado de signos desprovidos de clareza, que requerem um esforço de interpretação, de dotação de significado. Mesmo o convertido trabalha com sinais. Deixar de estar na escuridão seria deixar de ser homem. ${ }^{5}$

Essa consideração de ocultamento generalizado para toda verdade é peça fundamental na consideração da natureza humana para Pascal e, portanto, para a natureza do conhecimento, inclusive dos primeiros princípios. Dada a corrupção, é necessário que tratemos as ações divinas como enigmas indecifráveis. A condição velada de Deus toma uma proporção fundamental na teologia: sem ela não há interpretação possível (o que parece contraditório). É necessário que se considere a verdade como oculta para que algum sentido possa surgir em meio a noite. Há aqui o que Lebrun chama de "advento de uma economia do sentido estranha a todo racionalismo" (Lebrun 8, p. 92). O projeto epistemológico que decorre dessa posição teológica e antropológica (pois a verdade da condição humana também está oculta), 
não se dá na tentativa de restabelecer uma união entre o infinito e o finito (superar a separação absoluta) - o que supostamente poderia vir através do conhecimento racional dos primeiros princípios do universo -, mas de instaurar a necessidade de se repensar a possibilidade do sentido no interior do mundo corrompido, ou finito. Tratase de aprender como se pode conhecer ainda que haja a condição velada das primeiras e últimas verdades (referentes aos infinitos). O ocultamento está nas Escrituras (modo eficaz de justificar as contradições e dissolvê-las), está no Universo (natureza, condição humana) e nos primeiros princípios do conhecimento.

\begin{abstract}
Afinal, que é o homem dentro da natureza? Nada em relação ao infinito, tudo em relação ao nada; um ponto intermediário entre tudo e nada. Infinitamente incapaz de compreender os extremos, tanto o fim das coisas como o seu princípio permanecem ocultos num segredo impenetrável, e élhe igualmente impossível ver o nada de onde saiu e o infinito que o envolve. (Pascal 11, p. 56)
\end{abstract}

Nós somos desproporção, estamos no "meio" entre dois infinitos (Ibid., p. 58). Desproporcionais tanto com relação ao infinito da grandeza do Universo, quanto com relação ao infinito da pequenez dos corpos em que nos encontramos. Não podemos vislumbrar os limites do Universo do mesmo modo em que não podemos abarcar o limite ao nada presente em cada objeto que nos cerca, assim como nós mesmos. Somos imperceptíveis no todo assim como somos um mundo com relação ao nada (Ibid., p. 56). Inadvertidamente, segundo Pascal o homem escorrega na tentação de acreditar que possui a capacidade de conhecer os primeiros princípios da natureza, no entanto está tão longe quanto o conhecimento do tamanho do universo. Isso é ser homem, ser desproporcional. Origem e fim são dois extremos por natureza inalcançáveis pelo homem. Apesar de se encontrar entre estes dois, difere dos mesmos, sendo desproporcional com relação a si mesmo, pertencendo a nenhum lugar e a todo lugar ao mesmo tempo.

É evidente aqui a oposição pascaliana com relação à concepção de conhecimento para Descartes. Segundo este último, ainda que não possamos compreender Deus, podemos ter Sua ideia (conforme a terceira meditação). E essa condição faz com que o sujeito cartesiano esteja autorizado a considerar suas verdades como representativas de um mundo exterior. De fato, para Descartes conhecemos a essência dos objetos (extensão). Não há segredo impenetrável como há 
em Pascal. A comunicação entre as três ordens da realidade - Deus, espírito e corpo estabelecida nas meditações torna-se impossível. A desproporção ou heterogeneidade radical entre as diversas realidades, como o infinito e o finito, Deus e homem ou espírito e corpo, implicam na impossibilidade da consideração de natureza ontológica que tome os princípios da razão como fundamento do corpo.

O que devemos nos perguntar no momento é o seguinte: como é possível que haja conhecimento para Pascal, dada toda essa condição humana corrompida que acabamos de expor? Se, para Descartes, o problema do conhecimento resolve-se com uma complicada consideração de um método universal e da meditação da individualidade de um sujeito e sua relação com Deus, para Pascal é necessário que haja algo que sustente as verdades mais simples do conhecimento, a partir das quais é possível ter um determinado grau de certeza em nossas proposições, seja nas ciências exatas, seja no conhecimento da natureza ou do homem.

Pascal é um cientista admirável. Chegou a escrever tratados de física inovadores para a época. Sua ciência é dada a partir da experiência. Para ele, o papel da razão não é a descoberta dos princípios, mas a operação destes e a descoberta de significados a partir deles. Essa limitação da razão é facilmente percebida no caso em que se tenta provar uma verdade primitiva. O que acontece é a complicação do elemento simples, tornando-o algo outro, e não definindo a si mesmo. No opúsculo Do Espírito Geométrico, Pascal pergunta: “Que necessidade há de se explicar o que se entende pela palavra homem?" (Pascal 12, p. 20) O mesmo serve para espaço, tempo, movimento, e todas as noções mais simples que se pode imaginar. $\mathrm{O}$ conhecimento do homem funciona a partir da aquisição, na ordem da operação sensitiva, da clareza de certas noções primitivas. A razão, enquanto faculdade cogitativa, entra em jogo para a elaboração (dedução) a partir destas noções básicas, e não para a elaboração de suas provas ou demonstrações, que são desnecessárias. Está aí o erro daqueles que tentam demonstrar os primeiros princípios, seja da geometria, seja de qualquer outra ciência, como a moral, por exemplo.

É aí que entra o que indicamos anteriormente a respeito da não centralidade da faculdade cogitativa no conhecimento para Pascal. No opúsculo mencionado, é muito interessante como a geometria é tomada como um caso para a explicação da natureza do conhecimento humano em geral. É muito representativo que seja essa a ciência: primeiro porque Pascal era perito nas ciências exatas, segundo porque é nela que se 
poderia supor a presença de uma razão autônoma, que de nada precisa para estabelecer suas verdades - independente. E uma terceira razão, não menos importante, é a ciência que Descartes toma como modelo para a compreensão de sua mathesis universalis. Para Pascal, é muito significativo o fato de que a geometria não pode demonstrar suas verdades mais básicas. Não se pode definir número, mas é evidente que é verdade que um número possa ser aumentado.

Está aí a exposição para Pascal da funcionalidade do conhecimento, que podemos ver ser coerente à visão teológica e antropológica exposta anteriormente. Nada mais natural que a geometria, uma vez que é um modo do conhecimento humano, seja expressão da condição da natureza humana: infinitamente distante do conhecimento dos primeiros princípios e de todas as infinitas consequências. O detalhe que observaremos agora é o seguinte: isso não a torna incerta. A convicção da certeza dos primeiros princípios é decorrente não da ordem das operações do entendimento, mas do sentimento. E se não fosse assim, não haveria ciência.

Todas estas verdades não podem ser demonstradas e, no entanto, são os fundamentos e os princípios da geometria. Mas como a causa que os torna impossíveis de demonstração não é a sua obscuridade, mas, pelo contrário, sua extrema evidência, essa falta de prova não é um defeito, mas antes uma perfeição. (Pascal 12, p. 25)

Olhando agora pelo lado positivo (construtivo) do conhecimento, deve-se compreender a falta de prova não como expressão do sentido oculto que há em todas as verdades da condição humana (obscuridade), mas como a expressão da extrema evidência de seus princípios. Em última análise, de fato a obscuridade teria a última palavra, no entanto, para Pascal a ciência é feita a despeito de sua fundamentação metafísica. Não preciso ter a certeza baseada em um conhecimento de Deus para saber que o vácuo pertence à nossa natureza observável. Para isso, fazem-se experimentos, submete-se a razão aos sentidos e tiram-se as conclusões. Se posso afirmar que essas verdades realmente existem e se posso ter certeza absoluta que não estou sendo enganado por um Deus enganador, é outro passo. Esses são argumentos da razão que parecem poder colocar em dúvida tudo que se apresenta.

Portanto, o fato de não poder provar tudo, não faz com que a ciência seja frágil, duvidosa. Isso porque sua perfeição não decorre de uma certeza absolutamente 
racional, no sentido cartesiano do termo. A luz natural não é a capacidade de tudo conhecer através da razão, mas é a certeza de princípios mais básicos, que não decorrem da razão, mas do que Pascal atribui à ordem do sentimento.

Nenhuma tentação, neste caso, de mathesis universalis. Pascal tem o sentimento muito vivo das cesuras entre as regiões do saber; é muito precavido contra toda metabasis, contra toda transferência abusiva de um método para fora de seu domínio de origem. Distingue, pois, as ordens ao invés de confundi-las. (Lebrun 8, p. 30)

Vemos que, do ponto de vista filosófico, em Pascal, há um certo pragmatismo com relação ao conhecimento semelhante ao que atribuímos às ciências experimentais na introdução deste trabalho. Em alternativa à busca solitária para determinação da base comum do conhecimento na razão, há aqui o reconhecimento do saber como um campo de objetos por natureza distintos, o que implica na consideração de distintos modos de conhecimento, assim como faculdades. A semelhança entre a postura do cientista experimental e a filosofia pascaliana se encontra na concepção da faculdade cogitativa (razão) como detentora de limites e na consequente consideração de instâncias alternativas como termos de conhecimento.

Para concluir, é importante introduzirmos uma distinção entre esta crítica de Pascal e a posição de Hume. Como já observado, ambos os autores apresentam a necessidade da consideração da ordem do sentimento como instância alternativa para os princípios do conhecimento. No entanto, o sentimento não deve ser tomado como algo semelhante nos dois casos, sendo necessário distinguir o sentimento em Pascal das sensações humeanas. Pascal não defende que os princípios do conhecimento tenham origem e formação nas impressões sensíveis, como ocorre em Hume. Através do conceito de coração, Pascal compreende a faculdade a qual é atribuída o sentimento dos princípios, indemonstráveis do ponto de vista exclusivo das operações da racionalidade. $\mathrm{O}$ coração, expresso no devido sentido epistemológico no fragmento 282 (edição Brunschvicg), deve ser entendido como equivalente à ideia de luz natural pascaliana, conforme apontada nas linhas que se seguiram. ${ }^{6}$ É através dele que os primeiros princípios são sentidos e se mostram como conhecimentos indubitáveis, obtidos de maneira imediata, em contraste aos que se dão com a mediação dos dados sensíveis; assim como aos que se dão com a mediação do discurso, que é o caso do 
conhecimento obtido pela razão. Nesse artigo, procuramos explorar com mais detalhe a rejeição da metafísica cartesiana, ou da exclusividade da racionalidade, como fundamento do conhecimento; ainda assim, é necessário atentar para essa distinção apresentada.

\section{Hume: origem e limite epistemológico nas impressões.}

Assim como Pascal coloca uma incógnita como princípio de inteligibilidade da condição humana - através da teologia da queda (pecado original) - Hume parece tampouco abrir mão do fato de que a experiência humana resiste a uma definição universal, que seria de direito precedente às demais. Todo o conhecimento para Hume ocorre com base na experiência, e o mesmo serve para a natureza humana. A limitação que se tem para conhecer um objeto externo é semelhante a que se tem para conhecer a própria natureza humana: todo conhecimento é baseado em impressões. No caso da natureza humana, torna-se mais próximo o saber pois temos uma gama mais variada de impressões que nos dizem a seu respeito: além das impressões dos sentidos, temos também as impressões de sensações, por exemplo (dor, prazer); e também as impressões de reflexão (medo, desejo). Afinal, toda impressão diz respeito à natureza humana, mesmo aquelas que decorrem de objetos, pois suas características são vistas como decorrentes da forma da percepção humana. Toda impressão é, antes de tudo, humana. E, por isso, no início do Tratado, Hume afirma que a única fundação sólida para as ciências é a ciência da natureza humana: porque sem ela, não há certeza possível em qualquer ciência. ${ }^{7}$ No entanto, assim como não se pode afirmar pela razão algo do objeto que vá além das impressões, o mesmo ocorre a respeito da natureza humana. A grande surpresa dessa proposta humeana no início do Tratado é a seguinte: a fundação sólida é constituída por algo de que não se pode saber os primeiros princípios.

A essência da mente sendo-nos tão desconhecida para nós quanto a dos corpos externos, deve ser igualmente impossível formar qualquer noção de seus poderes e qualidades de outra forma que não seja por meio de experimentos cuidadosos e precisos [...] e qualquer hipótese que pretenda revelar as qualidades originais e últimas da natureza humana deve imediatamente ser rejeitada como presunçosa e quimérica. (Hume 6, p. 22)

Que solidez é essa que pode acontecer sem que haja o conhecimento de princípios primeiros e inabaláveis? Vemos nas palavras de Hume claramente o 
ceticismo a respeito do saber universal pretendido por Descartes, no entanto vemos também a pretensão de uma ciência que se pretenda certa - o próprio Tratado está aí para provar isso. O conhecimento deve ser buscado por "experimentos cuidadosos e precisos" (Ibid.). Toda inferência verdadeira deve ser posta à prova pela experiência, sendo esta última o material primeiro e último do conhecimento. É importante que haja a anterioridade da ciência da natureza humana, para justamente apontar esse tipo de entendimento: não é legítimo que a razão se pronuncie a respeito de algo que vai além das impressões. Isso se deve ao fato de que não há nada presente no espírito que não seja percepções. ${ }^{8}$

Abandona-se a ideia de que o entendimento seria capaz de apreender a essência dos objetos ou mesmo uma essência da natureza humana. É aí que entra o conceito de crença para o filósofo inglês: a identidade do objeto e do sujeito, as relações de causa e efeito, são da ordem da imaginação, ou da sensação. Não é através da razão ou do entendimento que se pode explicar as propriedades mais gerais de um objeto, mas unicamente através do hábito. É a repetição de uma associação específica de dados de impressão que me faz acreditar na existência de uma razão de explicação por trás das impressões. Qualquer proposição universal a respeito da experiência, por exemplo uma que procure abarcar primeiros princípios do conhecimento, já se inicia equívoca de imediato, uma vez que tem a pretensão de superar o caráter eminentemente empírico do conhecimento humano. Qualquer princípio que se deseje alcançar, há de ser enunciado sobre o funcionamento de nossos hábitos de associação de impressões. E é nesse ponto que entra a natureza: o modo como constituem as associações - ou seja, o habituar-se - acontece à revelia do sujeito, segundo leis que a natureza humana impõe, e não a razão. Não há fundamento racional para se pensar na unidade do objeto ou do sujeito, mas é inegável que esse pensamento ocorre. Hume conclui que nosso conhecimento não precisa necessariamente fundamentar-se na razão. A identidade do objeto não é demonstrável do ponto de vista da razão, mas isso não implica que se deve calar a respeito dela ou mesmo que se evite tomar o objeto como termo de conhecimento.

O reconhecimento de que a natureza, por meio do instinto do hábito nos obriga a raciocinar e crer, faz com que a ausência de justificação deixe de ser um problema. Há um bom uso do argumento cético que se opõe ao mau uso que o cético dele faz: não devemos usá-lo para suspender o juízo, 
mas para mostrar que a razão não é o fundamento de nossos raciocínios, e sim a imaginação. (Smith 13, p. 109)

Com as devidas mediações, podemos ver em Hume algumas semelhanças com o que Pascal chama de "ponto intermediário". Como vimos, para este último, o homem só pode conhecer aquilo que faz consigo mesmo uma proporção possível, ou seja, não se pode conhecer os fins últimos e nem os primeiros princípios do objeto, mas se pode conhecer uma série de propriedades e retirar delas consequências, desde que o conhecimento se mantenha na proporção do homem (ainda que sempre haja a desproporção, já que, para Pascal, os primeiros princípios estão ali, somos nós que não podemos apreendê-los). Podemos apreender princípios como "o todo é maior que a parte" ou o significado de termos primitivos como o tempo, homem, espaço; ou seja, tudo que faça uma possível proporção conosco. ${ }^{9}$ Para Hume, acontece algo parecido no sentido em que o homem só pode conhecer aquilo se apresenta para ele. Há em ambos os casos uma rejeição categórica da possibilidade do discurso metafísico, em que a razão é vista como faculdade de apreender princípios para além da experiência. Seja o objeto externo, seja a natureza humana, o único meio de conhecimento é a rigorosa investigação das impressões, tanto internas quanto externas - fenômenos. São as impressões na medida em que são distinguíveis (proporcionais) pelo homem e o modo como se associam entre si (natureza e imaginação) que podem ser objeto de conhecimento.

Essa é a regra e a limitação do conhecimento humano: só se pode falar com certeza daquilo que se apresenta (ou se apresentou um dia) para o sujeito como impressão ou associação de impressões. Enuncia-se a respeito de causa e efeito, mas deve-se ter em mente que não se trata mais do que um modo forte e constante de associação de impressões (bem diferente do que é concebido por Descartes, que dá estatuto ontológico ao princípio de causalidade). Toda ideia teve em sua origem uma impressão. Uma vez ideia, esta pode fragmentar-se (como de um corpo extrai-se o pé ou a cabeça), associar-se livremente com outras ideias e gerar ideias complexas. A condição de verdade para a ciência humeana é que a proposição possa encontrar na experiência a sua comprovação. Entenda-se por experiência não apenas as impressões, mas o modo em que estas impressões se dão para meu espírito - e esse modo é determinado pela natureza. ${ }^{10}$

Está aí a natureza do conhecimento para Hume: não há nada para além das impressões que pode ser apreendido racionalmente pela natureza humana, no entanto, 
percebe-se a presença de regularidades na experiência (como a identidade de um objeto e do sujeito ao longo do tempo, as relações de causa e efeito, ...), e essas regularidades serão o objeto de ciência, não um conhecimento que encontrará regras universais a respeito da natureza em si, mas que encontrará regras quase gerais a respeito do modo como a natureza se apresenta para o homem. A possibilidade de se estabelecer uma verdade acerca de um objeto, ou mesmo de se usar o objeto como termo de conhecimento, é dada pela consolidação do modo como a natureza se apresenta ao homem. Assim, vemos que o conhecimento, para Hume, é absolutamente fundado numa relação entre homem e natureza, em que nada há de estável do ponto de vista da razão, mas sim do ponto de vista da repetição de um modo de aparecimento da natureza aos meus sentidos e ao meu pensamento.

Assim como em Pascal, se dependêssemos apenas da razão, a ciência estaria arruinada. Há de haver outro fundamento para o conhecimento científico que não uma razão de natureza exclusivamente cogitativa, autônoma e independente. Vimos em Pascal que esse fundamento é o sentimento de certos princípios. Sob esse ponto de vista, Hume não parece ser muito diferente. Ambos colocam na natureza, na ordem da sensação, a possibilidade de fundamentação do conhecimento. Não pode haver fundamentação do ponto de vista filosófico, na medida em que este opera exclusivamente com a razão. Hume coloca o fundamento em uma consolidação de hábitos, ou seja, em última instância, não há nada que me possa garantir que o sol nascerá amanhã ou que este corpo cairá quando eu soltá-lo. Nada para além da minha expectativa que se cria através das experiências anteriormente vividas. Não sou capaz de encontrar um princípio racional para além dessa repetição de experiências. Quando tento fazer isso, não estou fazendo mais do que ilusão, supondo que o homem seria capaz de encontrar uma verdade da natureza em si, quando o que faz apenas é falar sobre aquilo que seus sentidos apresentam com repetição.

A natureza, por uma necessidade absoluta e incontrolável, determinou-nos a julgar, assim como a respirar e a sentir. (Hume 6, 216)

[A geometria] só supõe coisas claras e constantes pela luz natural e é por isso que é perfeitamente verdadeira, porquanto a natureza a sustenta na falta de discurso. (Pascal 12, p. 19) 
Luz natural para Pascal é exatamente a clarividência que há nos princípios indemonstráveis, que, segundo este trecho aí disposto, são dados naturalmente, pela relação entre homem e natureza. Se há algum fundamento na geometria, há de ser a natureza, e não a razão humana que pode tudo abarcar, através da intuição e dedução, como queria Descartes. Da mesma forma para Hume há a consideração da natureza como fundamento.

Ambos escapam dos argumentos céticos através do apelo à força impositiva da natureza sobre a experiência. Radicalmente diferente de Descartes, que julga escapar do ceticismo através da abstração de todo mundo exterior e apreensão da certeza fundamental a partir da aplicação do método racional, numa meditação acerca de sua natureza e da ideia de Deus. Há aqui a pretensão de homogeneidade entre a razão humana e as verdades em si da natureza. Tanto Pascal como Hume são conscientes da heterogeneidade entre razão e natureza. Ambos colocam na base do conhecimento racional uma faculdade sensitiva, o que produz uma nova concepção para a própria noção de razão, quando comparada a Descartes.

Para finalizar, devemos lembrar da distinção introduzida algumas páginas atrás: a semelhança entre os dois autores, expressa pela consideração da ordem do sentimento como alternativa à concepção cartesiana de fundamento do conhecimento, não implica que a posição nos dois casos seja a mesma. Buscamos demonstrar neste texto, prioritariamente, a semelhança e o modo como os dois autores fazem a crítica; no entanto, reforçamos que é necessário atenção para a diferença entre a compreensão do sentimento enquanto fundador, nos dois casos. Em Pascal, a faculdade sensitiva responsável pelos primeiros princípios é o coração, o que difere do que é posto por Hume, através da consideração do fundamento nas impressões. No primeiro caso, não vemos a redução da ciência ao limite da experiência sensível, ou seja, não se constitui segundo esse ponto de vista uma concepção de ciência estritamente empírica.

\section{Conclusão}

Buscamos desenvolver nesse trabalho uma reflexão acerca da abordagem filosófica pascaliana e humeana no que diz respeito aos primeiros princípios do conhecimento. Para tanto, foi importante considerar o modo como ambos se posicionam a respeito das limitações do conhecimento ou da razão, assim como o 
modo como se opõem à concepção cartesiana de conhecimento. Vimos que ambos constroem essa posição através de uma investigação acerca da natureza humana. Pascal encontra respostas para essa pesquisa antropológica tanto numa reflexão de natureza religiosa (desproporção do homem), como filosófico-científica (princípios da geometria são indemonstráveis). Hume, por sua vez, limita-se à reflexão filosóficocientífica, expressa no Livro I de seu Tratado sobre a Natureza Humana, em que apresenta a perspectiva cética com relação à razão, assim como a explicação a respeito da possibilidade do conhecimento.

Vimos que ambos excluem a ideia de que a razão por si só pode ser considerada como a pedra fundamental da ciência. Para os dois, a razão deve partir de certos princípios que são necessariamente não racionais, que estariam mais para a ordem da sensação do que das operações racionais. E por aí acreditamos ter desenvolvido nesse trabalho o que chamamos de anticartesianismo dos dois filósofos a respeito dos princípios do conhecimento. A oposição a Descartes é fundamental. Enquanto este último considera necessário para a fundamentação do conhecimento o movimento abstrativo da razão de voltar a si mesma (cogito), os outros dois defendem a necessidade de que a razão parta de algo já dado.

A ideia de uma disciplina puramente racional que fundaria todas as outras seria então um engano. Para Hume, a base sólida das ciências é a ciência da natureza humana, em que se encontra o modo como o conhecimento (toda ideia) é sempre fundado nas impressões. Não há ideia que não tenha sua origem (consequentemente conteúdo) nas impressões (seja interna ou externa), portanto, não há modo de funcionamento puramente racional a priori da experiência. O conhecimento começa nas impressões e no modo como elas podem se relacionar entre elas. Desse ponto de vista, caso se queira fundamentar o conhecimento na razão, é necessário que esta sofra uma grande alteração de significado e passe a abarcar também a parte sensitiva da experiência.

Para Pascal, a razão tampouco aparece como faculdade responsável pela apreensão dos primeiros princípios. No fragmento 72 dos pensamentos vemos o caráter desproporcional o homem com relação à natureza, que o excede infinitamente para a menor e a maior escala. O opúsculo do Espírito Geométrico mostra bem como a ciência pode funcionar muito bem sem que haja a fundamentação racional de suas inferências. A razão parte de certos princípios apreendidos na ordem sensitiva, dados através do coração. 
Nos dois casos, ciência e ceticismo parecerem caminhar lado a lado, mas não com pouca tensão. Não há fundamento demonstrável do ponto de vista da discursividade racional, mas é inegável que há conhecimento. Trata-se de algo distinto da filosofia antiga que declara a necessidade da suspensão do juízo generalizada. O ceticismo com relação à razão permanece o mesmo - ambos têm consciência de que a razão por si só é autodestrutiva, ou seja, é sempre capaz de pôr tudo em dúvida -, o que muda é que há a estipulação de uma origem distinta, da qual os primeiros princípios tornam-se inquestionáveis. E esse é o papel da natureza nos dois casos. Está aí o anticartesianismo que pretendemos demonstrar nesse trabalho.

\section{REFERÊNCIAS BIBLIOGRÁFICAS}

1. DESCARTES, R. Meditações in Os Pensadores. Trad. J. Guinsburg e Bento Prado Júnior. São Paulo: Abril Cultural, 1973.

2. Regras para orientação do espírito. Trad. Maria Ermantina de Almeida Prado Galvão. São Paulo: Martins Fontes, 2007.

3. JAFFRO, L. La nature de l'esprit: Hume ou Pascal? Conferência proferida no Departamento de Filosofia da USP, em maio 2013.

4. GOUHIER, H. Blaise Pascal: conversão e apologética. Trad. Éricka Marie Itokazu e Homero Santiago. São Paulo: Discurso editorial, 2005.

5. HUME, D. Investigações sobre o entendimento humano e sobre os princípios da moral. São Paulo: Editora Unesp, 2004.

6. . Tratado da natureza humana. Tradução Débora Danowski. São Paulo: Editora Unesp, 2009.

8. LEBRUN, G. Blaise Pascal. São Paulo: Brasiliense, 1983.

9. MALHERBE, M. La philosophie empiriste de David Hume. Paris: Vrin, 1985.

10. MICHAUD, Y. Hume et la fin de la philosophie. Paris: PUF, 1981.

11. PASCAL, B. Pensamentos in Os Pensadores. Trad. Sérgio Milliet: São Paulo, Abril Cultural, 1971.

12. . Do espírito geométrico e outros textos. Trad. Antonio Geraldo da Silva. São Paulo: Escala, 2006.

13. SMITH, P. J. O Ceticismo de Hume. São Paulo: Loyola, 1995. 
14. A Dívida de Hume com Pascal. Kriterion, Belo Horizonte, no 124, Dez/2011, p. 365-384.

\title{
ON ANTI-CARTESIANISM WITH REGARDS TO THE FIRST PRINCIPLES OF KNOWLEDGE IN PASCAL AND HUME
}

\begin{abstract}
The purpose of this paper is to reflect upon the Anti-Cartesian perspective expressed in the works of Pascal (1623-62) and Hume (1711-76), specifically regarding the philosophical conception of the first principles of knowledge. Starting from the enunciation of the mathesis universalis in Descartes, we seek to identify how Pascal and Hume conceive an alternative position, and reflect upon the similarities and differences between these two authors. The primary sources of Pascal's work which will be considered are the opuscule The Geometric Spirit (1656, partially published in 1728) and fragment 72 (Brunschvicg edition) from Thoughts (1670). In Hume, the focus is on Part I from Book I of the Treatise of Human Nature (1739-40) and An Enquiry Concerning Human Understanding (1748). Keywords: Hume, Pascal, Anti-Cartesianism, principles, knowledge.
\end{abstract}

\section{NOTAS}

\footnotetext{
${ }^{1}$ Essa metáfora foi utilizada por Descartes no início da Regra IV (Descartes 2, p. 19).

${ }^{2}$ Ordem e Medida aqui dizem respeito ao modo de funcionamento fundamental da razão e devem ser compreendidas aqui para além de quantidades. Portanto, são distintas de ordem e medida no caso das matemáticas comuns, ainda que estejam em sua origem. Estas últimas seriam apenas uma veste do que é a disciplina primeira do conhecimento. Nas Regras para orientação do espírito, podemos ver Descartes desenvolvendo estes dois conceitos no sentido da mathesis universalis.

${ }^{3}$ Gouhier chega a afirmar que existem ao menos seis métodos em Pascal.

${ }^{4}$ Sobre isso, ver Lebrun 8, cap. V: Sinais da Noite.

${ }^{5}$ Sobre isso, ver Ibid., cap. III, que esclarece também a respeito do que foi considerado o ponto de heresia de Port-Royal e de como essa perspectiva teológica é decorrência de uma tomada de posição agostiniana.

${ }^{6}$ No fragmento 282 (edição Brunschvicg), Pascal diz: “o coração sente que há três dimensões no espaço e que os números são infinitos; e a razão demonstra em seguida que não há dois quadrados dos quais um seja o dobro do outro. Os princípios se sentem as proposições se concluem e tudo com certeza embora por vias diferentes".

7 "Não existe nenhuma questão importante cuja decisão não esteja compreendida na ciência do homem; e não existe nenhuma que possa ser decidida com alguma certeza antes de conhecermos essa ciência." (Hume 6, p. 22)

8 "Na realidade, jamais avançamos um passo sequer além de nós mesmos, nem somos capazes de conceber um tipo de existência diferente das percepções que apareceram dentro desses estreitos limites. Tal é o universo da imaginação, e não possuímos nenhuma ideia senão as que ali se produzem." (Ibid., p. 95)

${ }^{9}$ Sobre a ideia de termos primitivos em Pascal, ver Pascal 12.

${ }^{10}$ Interessante verificar esta breve explicação de como a ideia de extensão surge de uma relação de impressões: "Ao abrir meus olhos e dirigir o olhar para os objetos à minha volta, percebo vários corpos visíveis; quando novamente os fecho, e considero a distância entre esses corpos, adquiro a ideia de extensão. Como toda ideia é derivada de uma impressão que lhe é exatamente similar, as impressões similares a essa ideia de extensão devem ser ou bem sensações derivadas da visão, ou bem impressões internas oriundas dessas sensações.” (Ibid., p. 59)
} 